Southern Illinois University Edwardsville

SPARK

SIUE Faculty Research, Scholarship, and Creative Activity

7-18-2011

\title{
Consortial Cataloging Guidelines for Electronic Resources: I-Share Survey and Recommendations
}

\author{
Kristin E. Martin \\ Judith Dzierba \\ Lynnette Fields \\ Southern Illinois University Edwardsville, lfields@siue.edu \\ Sandy K. Roe
}

Follow this and additional works at: http://spark.siue.edu/siue_fac

Part of the Cataloging and Metadata Commons

\section{Recommended Citation}

Martin, Kristin E.; Dzierba, Judith; Fields, Lynnette; and Roe, Sandy K., "Consortial Cataloging Guidelines for Electronic Resources: I-Share Survey and Recommendations" (2011). SIUE Faculty Research, Scholarship, and Creative Activity. 21.

http://spark.siue.edu/siue_fac/21

This Article is brought to you for free and open access by SPARK. It has been accepted for inclusion in SIUE Faculty Research, Scholarship, and Creative Activity by an authorized administrator of SPARK. For more information, please contact gpark@siue.edu. 


\section{Cover Page Footnote}

This is an Accepted Manuscript of an article published by Taylor \& Francis in Cataloging and Classification

Quarterly on July 18, 2011, available online: http:// dx.doi.org/10.1080/01639374.2011.588996 
Consortial Cataloging Guidelines for Electronic Resources: I-Share Survey and Recommendations

Authors:

Kristin E. Martin, University of Illinois at Chicago Judith Dzierba, Rush University Medical Center Lynnette Fields, Southern Illinois University Edwardsville Sandy K. Roe, Illinois State University

Electronic resources have been a growing portion of library collections. , Concurrent with their growth in numbers has been the need for libraries to manage their access, including through the library catalog. Libraries have addressed the need to represent e-resources in their catalogs by modifying and transforming cataloging rules originally designed to handle physical items, and by developing new workflows and guidelines. Since 2000, the Consortium of Academic and Research Libraries in Illinois (CARLI) and its predecessor, the Illinois Library Computer Systems Organization (ILCSO), have created three working groups to address cataloging practice and catalog access to e-resources for member libraries participating in the shared union catalog (currently the I-Share union catalog). The third of these, the Cataloging Electronic Resources/Electronic Resources Display in the OPAC Task Force (2009) (hereafter 2009 Task Force), was to build upon and update work done by the previous iterations of the Task Force and update recommendations created in 2004. The 2009 Task Force, of which the authors of this paper were members, was given the following charge:

- Document needed changes to the 2004 Report and provide additional recommendations as appropriate.

- Identify current best practices and additional issues related to the cataloging of, access to, and display of electronic resources in I-Share's consortial environment.

- Identify related issues concerning access to electronic resources that are outside of this charge and make recommendations to the I-Share User's Group for additional action. ${ }^{1}$

In 2003 the second Task Force surveyed library consortia from around the United States as they determined how to revise the existing recommendations. ${ }^{2}$ Rather than perform another national survey, 
the 2009 Task Force chose to focus its efforts in a more inward direction and designed a survey to collect information about how I-Share members handle e-resources cataloging issues, their awareness of and compliance with the existing consortial recommendations, and challenges faced in e-resources cataloging practices. These 2010 survey results provide a snapshot of a group of libraries' cataloging practices. The survey, which covers all types of e-resources, and the recommendations that were developed from it, provides a rarely found example of an attempt to identify and to address major issues surrounding e-resources cataloging, regardless of format or record source. Libraries participating in the survey cover a wide variety of academic libraries, including libraries at large research institutions, small private liberal arts schools, community colleges, and libraries at specialized research institutions. This paper reports on the results of that survey and the recommendations developed by the 2009 Task Force. It will be of interest to other libraries and consortia considering their own cataloging practices in this environment of continued growth in electronic access and new methods of discovery and access.

\section{Literature Review}

This review explores the literature describing e-resources cataloging and access as it relates to the scope of the charge given to the 2009 Task Force. Different areas of the literature have focused on all of the areas covered by the Task Force work, but no one piece has synthesized e-resources cataloging practice across all formats and for records from all sources. Instead, the individual studies tend to focus on e-resources by format (e.g., electronic journals or electronic books), by record source (e.g., cataloging individually or obtaining vendor records), or focus on methods of access (e.g., A-Z lists versus individual records in the catalog). The review of the literature is divided up into the following sections: library surveys and practices; consortial guidelines; national guidelines; and future directions for providing information access. 


\section{Library Surveys and Practices: Electronic Journals}

The literature contains reports of multiple surveys conducted over the past several years to determine how academic libraries are coping with the challenges of cataloging electronic journals (ejournals). The 2003 survey of U.S. consortia and academic libraries performed by the second iteration of the CARLI Task Force provides one such example. Although the survey reported on cataloging all types of e-resources, the questions and responses focused mainly on e-journals. The survey questions that elicited the highest rate of response included topics such as the primary means of access to e-resources (catalog or Web lists), the single-record or multiple-record approach, and the placement of URLs in the bibliographic or holdings records. ${ }^{3}$ Two years later, O'Hara surveyed 145 academic libraries and found that the survey respondents were still grappling with similar issues. ${ }^{4}$ She stated, "academic libraries seem to be no closer to establishing best practices in cataloguing electronic journals than they have ever been. Almost as many libraries have switched from separate to single records as have switched from single records to separate records since they began cataloguing electronic journals." ${ }^{5}$ Survey results revealed that most libraries were providing web-based lists in addition to catalog records, and for some libraries OpenURL link resolvers were becoming a second catalog. In another 2005 study, Cuddy and Bahr reviewed the websites of 138 U.S. and Canadian medical schools to determine how e-journals were made available to their users. Their research found that in most of the sample libraries, users had to search both the online catalog and a web-based list to learn all of an institution's e-journal holdings. ${ }^{6}$ Libraries cataloging e-journals have turned to vendor records to enhance their catalogs' holdings. O'Hara noted that catalog records for e-journals are widely available from publishers, aggregators, and commercial services, and that has made it easier for libraries to include these records in their catalogs. Nevertheless, she concluded that libraries are in a state of transition and librarians are still struggling with ways to provide access to electronic journals. ${ }^{7}$ In a 2008 random sample of academic libraries, Chen and Wynn found that an increasing number of libraries had either partially or entirely 
given up manual cataloging of e-journals in favor of batch loading purchased MARC records, and that libraries increasingly direct users to tools other than the catalog when they are looking for e-journals. ${ }^{8}$ Collins' interviews with serials librarians at academic institutions revealed that relying on vendor record sets for the many changing collections of e-journals created overlay issues, multiple records in the catalog for the same title, and incomplete coverage for those collections without vendor records. Thus many reported using a third-party MARC record service for some or all of their e-journals cataloging. ${ }^{9}$ These services, such as Serials Solutions 360 MARC and ExLibris MARCit!, provide a way for libraries to rely on third-party vendors, as opposed to the publishers or providers, for records of e-journals to which a library subscribes. Generally, a link contained within each bibliographic record takes the user to a menu of aggregated electronic holdings for that journal. These services are especially beneficial when a library receives the same title through multiple databases and where aggregator databases are constantly adjusting content by switching titles and changing dates of coverage. However, quality in the records may be uneven because brief records, which may contain as little as a title and a URL, are used when full records are not available. A 2008 survey by Kemp indicated that the mean percentage of brief records was 20.2 percent for those who subscribed to a record service. ${ }^{10}$ Some libraries chose not to load brief records, reducing the fullness of coverage in the catalog, but improving the quality of the records. Despite the limitations of the MARC record services, most libraries in Kemp's survey felt the advantages outweighed the disadvantages.

Library Surveys and Practices: Electronic Books

Compared with e-journals, fewer surveys have been done on library electronic book (e-book) cataloging practice, although there are some examples. In 2007, Belanger examined the library catalogs of thirty higher education libraries in the United Kingdom. ${ }^{11}$ While almost all libraries (28 of the 30) provided some kind of title-level access in their catalog for at least some of their subscription-based 
collections, only four also provided records for free e-books. There was more consistency compared with e-journals on cataloging practice, as 23 of the 28 libraries reported using separate records for print and e-books, although a check of their catalogs revealed that many libraries used a combination of single records and separate records. In another 2006 review, Dinkelman and Stacy-Bates examined the websites and catalogs of Association of Research Libraries (ARL) member libraries. ${ }^{12}$ Fifty-six percent of the websites had separate pages devoted to e-books, but searching the online catalog for e-books was often difficult. They recommended improving search functionality through the catalog by adding a keyword search limit option for "e-books." In 2008, Hutton explored how catalogs and websites provide access to open-access digital collections. ${ }^{13}$ When Hutton searched for ten e-book titles in the online catalogs and websites of ten academic libraries, only three of the e-book titles were found in the library catalogs and none were found on library Web pages.

Although it has long been recognized that adding bibliographic records to the catalog for ebooks increases the discovery and use of these resources, ${ }^{14}$ libraries have been slow to catalog e-books partly due to the lack of guidance and the need to determine new workflows. ${ }^{15}$ An early example of guidance is Bothmann's 2004 article, which provides practical information on cataloging an e-book using the 2002 revision of the Anglo-American Cataloguing Rules (AACR2R). His article pre-dates the providerneutral guidelines but remains useful for its comprehensive analysis of the most relevant areas and fields. ${ }^{16}$ More recent literature related to e-book cataloging has focused on the availability of vendor records and the challenges of cataloging records in batch. Batches of records, supplied by vendors or MARC record services, can provide an efficient way for libraries to quickly provide catalog access to a large number of resources. However, vendor records come with their own set of challenges, including quality control and batch loading issues, as has been documented in the literature for U.S. depository materials, microform sets, and others types of library resources. ${ }^{17}$ Martin and Mundle categorized the problems found in a set of vendor records for Springer e-books into three categories: access issues that 
prevented users from accessing the resource from the catalog (e.g., broken URLs and missing records); load issues that prevent libraries from loading the records into the catalog (e.g., incorrect overlays of existing records, improperly coded diacritics); and quality issues in which information in the record hampers the users' ability to locate the record in the catalog (e.g., invalid subject and name access points, extraneous fields ). ${ }^{18}$ They recommended that consortia and libraries work together to improve the quality of vendor records and that negotiations for purchasing sets of e-resources include a discussion of record specifications.

The batch loading process also presents a new challenge to technical services departments accustomed to handling records on an individual basis, and requires a rethinking of cataloging workflows. Papers by Mundle, Mugridge and Edmunds, and Wu and Mitchell all detail experiences of batch-loading e-book vendor record sets at their respective libraries. The new workflow considerations include determining what sets are available to load, developing standards for evaluation and assessing record quality, editing and customizing the records, performing the load process, and ongoing quality assurance and maintenance. ${ }^{19}$ However, tools such as MarcEdit can help libraries evaluate and manipulate records in batch, as described in Sanchez et al., Martin and Mundle, and Wu and Mitchell, among others. ${ }^{20}$

As with e-journals, MARC record services such as 360 MARC Updates from Serials Solutions provide an alternative to individual record sets for e-books. ${ }^{21}$ Martin and Mundle note that using an ebook record service helps libraries both track and maintain access to their e-book collections, and simplifies the transition to the provider-neutral record model by having only one record for content offered through multiple providers, instead of libraries having to coordinate matches and overlays of records for the same content from different vendors. ${ }^{22} \mathrm{Wu}$ and Mitchell have made such a transition for the University of Houston Libraries, which allowed them to streamline their batch processing, since records are coming from a single source as opposed to multiple vendors each with their own 
customization requirements, although some of the records are brief records similar to the brief records for serials. ${ }^{23}$

\section{Consortial Guidelines}

The challenge of providing access to online resources, sometimes before all questions are resolved in the national cataloging standards, can be further complicated by the distributed environment of a consortium. In addition to CARLI, many organizations have created consortial guidelines for cataloging electronic resources. ${ }^{24}$ The Virtual Library of Virginia (VIVA) was established to provide a source of electronic collections and services for higher education institutions in Virginia, and in 1996 the VIVA Cataloging and Intellectual Access Task Force (VIVACAT) was formed and charged in part to develop guidelines for cataloging VIVA materials. ${ }^{25} \mathrm{O}$ 'Connell reported on Moeller and Baia's overviews of several consortia and the methods each had for documenting cataloging policies, the California Digital Library (CDL) in particular. ${ }^{26}$ More recently, McDonald and Johnston described the consortial issues that they needed to resolve relating to the cataloging of streaming videos. ${ }^{27}$ Throughout these discussions, common concerns surfaced consistently. These included the use of a single-record or a separate-record (multiple-record) approach for serials, the placement and type of URL, and the display and linking capabilities of library systems.

In another recent example, Preston detailed the activities of the OhioLINK consortium, which, in addition to developing guidelines for cataloging e-resources, developed a system and workflow for cooperative consortial cataloging of e-book collections purchased by the consortium. ${ }^{28}$ OhioLINK relies upon the work of a standing committee on data standards to set priorities and the use of member volunteers to divide up responsibilities and address the sometimes large number of titles to be cataloged. Once the standards were in place for cataloging e-book collections, OhioLINK faced additional organizational challenges of developing a workflow reliant upon the time of member volunteers. While 
not specific to library consortia, Sellberg's essay on the future of cooperative cataloging deserves mention here. Sellberg opined that "customizing catalog records for separate and independent online public access catalogs ... has held back progress toward the development of cooperative cataloging models that feature true resource sharing, rather than record copying." ${ }^{29}$ Sellberg believes that there is a definite place for cooperative cataloging if "one thinks about pooling the expertise of metadata experts and working together to facilitate use of the world's information resources through welldesigned and well-managed systems of access." ${ }^{30}$ Cooperative ventures such as the shared cataloging among the OhioLINK consortial libraries may represent a step in this direction.

\section{PCC National Guidelines}

National policies for aggregator-neutral and provider-neutral records for e-resources developed by the Program for Cooperative Cataloging (PCC) have also influenced libraries' cataloging decisions, whether for e-journals, e-books or other electronic formats. The aggregator-neutral record policy, implemented by CONSER (Cooperative Online Serials) in July 2003, was the first of such policies and designed to simplify the cataloging of e-journals. ${ }^{31}$ CONSER's previous policy of creating separate records for each aggregation of an e-journal had become confusing to end-users and difficult for library catalogers to sustain. The aggregator-neutral policy was intended to be applicable to all online serials, whether or not they are represented in packages, and whether or not they have a print counterpart. According to the aggregator-neutral policy, the bibliographic record representing an electronic serial should contain only information applicable to all versions of the electronic serial supplied by all providers, with URLs for all of the providers supplying the serial included in the single aggregator-neutral record. Similar policies have since been implemented for remote access integrating resources ${ }^{32}$ and for e-monographs, ${ }^{33}$ although the terminology "provider" was chosen to be more inclusive than 
"aggregator." Both policies were developed to reduce the number of multiple records representing the same resource.

Despite the obvious attraction of following the aggregator-neutral and provider-neutral guidelines, their use is not without challenges. Wu and Mitchell point out that while the providerneutral policy will greatly improve the cataloging landscape for e-monographs, few vendors have converted their existing records to the new provider-neutral format, and many continue to create bibliographic records with reproduction notes and package and provider names, thus ignoring providerneutral policy. ${ }^{34}$ Individual libraries must decide if they will convert their existing records, wait for the vendors to make the change, or just ignore the provider-neutral policy entirely. Other challenges mentioned by Wu and Mitchell include the lack of a reliable identifier to collocate different manifestations of the same resource, the quality and completeness of the MARC records supplied by vendors, and the lack of consistency in handling multi-volume sets. The aggregator- and provider-neutral guidelines direct a cataloger to describe more than one manifestation in one bibliographic record. This conflicts with the guidelines in Resource Description and Access (RDA), and so the implementation of RDA may affect the future of aggregator- and provider-neutral records. ${ }^{35}$

\section{Future Directions for Providing Information Access}

While most of the literature described thus far has focused on specific cataloging issues related to e-resources, it is also important to step back and consider e-resources access in the larger context of information discovery in a rapidly changing landscape, which was part of the 2009 Task Force's charge and scope of work. It is helpful to consider the Functional Requirements for Bibliographic Records (FRBR) user tasks when assessing the needs of the end-user: "to find materials that correspond to the user's stated search criteria ... to identify an entity ... to select an entity that is appropriate to the user's needs ... to acquire or obtain access to the entity described." ${ }^{36}$ Catalog displays generated from most 
integrated library systems do not currently model the entity-relationship concepts in FRBR well. Allgood identified this catalog display problem as, "multiple occurrences of titles available in different formats as multiple hits for a user's search query, rather than clustering them into a single entry or hit," ${ }^{\prime 37}$ and suggested that the FRBR model coupled with RDA and data mining technologies could resolve it. In her conference presentation, reported on by Wolverton, Antelman noted that libraries have created "A-Z lists to display electronic titles in a less cluttered manner," but these lists do not entirely solve the problem. ${ }^{38}$ Rather, Antelman demonstrated how an Electronic Resource Management (ERM) system could be used to display FRBR work-level information for the serial and its manifestations in the catalog as well as in the library's other databases.

Next generation catalogs and web discovery tools endeavor to match information-seeking behavior with Google/Amazon-like experiences and may affect cataloging practice. Vaughan reported on this progression toward the development of Web-scale discovery tools in the commercial arena and discussed their features for enabling seamless searches across large, centralized, pre-aggregated indexes for better outcome retrieval and display. ${ }^{39}$ In an interview submitted by Freeman, Vaughan responded, "Cataloging staff may change some practices, such as which fields are utilized in the ILS or digital collections record, given that some fields may be harvested and incorporated into the discovery service index and interface, and others not." ${ }^{40}$ Vaughan further recommended that since these new discovery services can make discrepancies highly visible, catalogers and metadata experts may want to begin quality assessments of the data in their records. Breeding described application programming interfaces (APIs), Web-services, and service-orientated architecture as they are used by discovery systems. Example projects mentioned in Breeding's report demonstrated that APIs can extract data from and communicate in real time with an integrated library system, taking advantage of structures that support the Web. ${ }^{41}$ Antelman, Lynema, and Pace described North Carolina State University's experimentation with Endeca's Information Access Platform, Guided Navigation and "record rollup" to 
enable clustering, faceted-navigation, and relevance-ranked keyword search results to increase correlations between individual catalog records and FRBR work-level displays. ${ }^{42}$ The eXtensible Catalog (XC) project (of which CARLI is a founding sponsor and contributor), under development at the University of Rochester, is anticipated by Bowen to be significant for engaging FRBR precepts to find, identify, select, and obtain library collections, digital and non-digital, in next generation discovery tools and open Web environments. ${ }^{43}$ This open-source application is being designed to harvest metadata from an ILS and transform it so it can be merged with other metadata (i.e., digital collections, repositories, licensed databases), giving individual libraries and consortia greater flexibility to customize displays. Nevertheless, a usability study on VuFind and WorldCat Local by Emanuel and Kern demonstrated that end-users, despite enhancements such as book covers, reviews, and tables of contents, and interaction with social media, want concise data in a single screen, will not take time to develop search strategies, rely solely on keywords, and rarely apply limits to search outcomes. ${ }^{44}$

\section{Description of Local Situation}

CARLI was formed on July 1, 2005 by the consolidation of three existing Illinois academic library consortia: Illinois Cooperative Collection Management Program (ICCMP), Illinois Digital Academic Library (IDAL), and Illinois Library Computer Systems Organization (ILCSO). CARLI currently has 152 members consisting of private and public academic and research institutions.

Seventy-six member libraries in CARLI also participate in the I-Share system, an integrated library system that provides participating libraries with an online catalog of their own collection as well as a merged, union catalog of the holdings of all I-Share libraries. I-Share members consist of 45 private academic institutions, 13 public academic institutions, 15 community colleges, two non-academic research institutions, and one state-funded high school. The I-Share Users's Group (IUG) coordinates the consortial aspects of the I-Share system and serves as the primary resource for identifying, evaluating 
and informing the CARLI Board on resource sharing and discovery issues. The I-Share Cataloging and Authority Control Team (ICAT) makes recommendations to IUG and the I-Share members on cataloging and authority control issues. CARLI appoints volunteers from I-Share libraries to serve on IUG and ICAT. CARLI maintains separate databases for each of its participating libraries, and the content of each database is combined and loaded to create the I-Share union catalog. Both the local catalogs and the I-Share union catalog use the Ex Libris Voyager integrated library system. ${ }^{45}$ As of June 1, 2010, VuFind, an open-source public catalog interface, provides the public interface for the I-Share union catalog. For their local catalogs, CARLI provides I-Share libraries with the options of VuFind or WebVoyáge, Voyager's public catalog module, to use for their catalog interfaces. As of February 2011, the distribution of libraries using various interfaces for their local catalogs is as follows: 43 libraries use VuFind as their primary interface, 28 libraries use WebVoyáge Classic, two libraries use WebVoyáge 7 (Tomcat), two libraries use OCLC's WorldCat Local, and one library uses EBSCO Discovery Service. Although CARLI manages the technical infrastructure, member libraries are responsible for the content of the records in their individual databases. All additions, changes, and deletions to each library's bibliographic records are loaded into the I-Share union catalog nightly. CARLI uses match points and ranking algorithms to add and delete holdings to existing bibliographic records and to determine if existing bibliographic records should be overlaid or new records should be added to the I-Share database. CARLI's preferred match point is the OCLC number or other unique vendor number. When a library chooses to load a set of bibliographic records obtained from OCLC or another vendor, CARLI coordinates with that library to batch load the record set into the individual library catalog; these records are subsequently loaded into the I-Share union catalog through the same nightly update process.

CARLI and its predecessor, ILCSO, recognized the need to develop guidelines for cataloging eresources as they became more prevalent within library collections. Prior to the creation of the 2009 
Task Force, two earlier iterations of the Task Force met in 2000/2001 and 2003/2004, respectively. The 2009 Task Force was established to build upon the update the work done previously. Members of the 2009 Task Force were Kristin E. Martin, Chair (University of Illinois at Chicago), Judith Dzierba (Rush University Medical Center), Lynnette Fields (Southern Illinois University Edwardsville), Andrea Imre (Southern Illinois University Carbondale), Sandy Roe (Illinois State University), Tammy Schnell (Lincoln Land Community College), Xiao (Helen) Zhou (University of Illinois at Urbana-Champaign), and Jessica Gibson, CARLI Staff Liaison..

\section{Survey Methodology}

The 2009 Task Force designed a survey to collect information about how I-Share libraries handle e-resources cataloging issues, awareness of and compliance with the existing consortial recommendations, and challenges faced in e-resources cataloging practices. The Task Force wrote and tested the survey during the fall of 2009, and then applied for and received Institutional Review Board (IRB) approval to administer the survey to I-Share member libraries. IRB approval was received from Illinois State University (2009-0469) as the lead institution, with Rush University, Southern Illinois University Carbondale, Southern Illinois University Edwardsville, and the University of Illinois at Chicago also obtaining approval from their respective Boards. IRB approval was not required by the other Task Force members' institutions. The survey of 37 questions is available in Appendix B of the final report. ${ }^{46}$

The survey was conducted online from February 18 to March 10, 2010. On February 18, a recruitment letter with a link to the survey on SurveyMonkey was sent via email to the designated technical service contact from each of the $76 \mathrm{I}$-Share libraries. On March 5, a reminder email was sent to

all contacts. Forty-five libraries (59 percent) completed the survey. Survey results were collected utilizing Survey Monkey and exported into spreadsheets and PDF files. To ensure the accuracy of the data, Task 
Force members reviewed all responses, eliminated duplications and incomplete data, and re-compiled the survey results.

\section{General Survey Results}

The questions in the survey cover four major areas related to e-resources cataloging:

1. Quantity and type of e-resources available through the catalog

2. Use of the single-record and separate-record approaches for cataloging e-resources

3. Batch loading and vendor records

4. Adherence to existing I-Share guidelines

Results from the first three categories are presented in this section, with responses related to adherence to existing I-Share guidelines placed within the context of the new recommendations and described in the section, 2009 Task Force Recommendations. Figure 1 provides a breakdown of the types of libraries in I-Share who responded to the survey. A higher percentage of public academic libraries responded. As these are some of the larger libraries participating in I-Share, they are more likely to have significant numbers of records for e-resources in their catalogs and may have been more inclined to participate in the survey. The margin of error for the data collected from 45 responses is 9.3 percent with a 95 percent confidence level for the data analyzed in its entirety. The confidence interval allows a 95 percent certainty that if all 76 I-Share libraries had actually responded, the results would vary by no more than 9.3 percent in either direction. The confidence interval for some of the questions where fewer libraries responded may be different. 


\section{Figure 1: I-Share Libraries Participating in Survey}

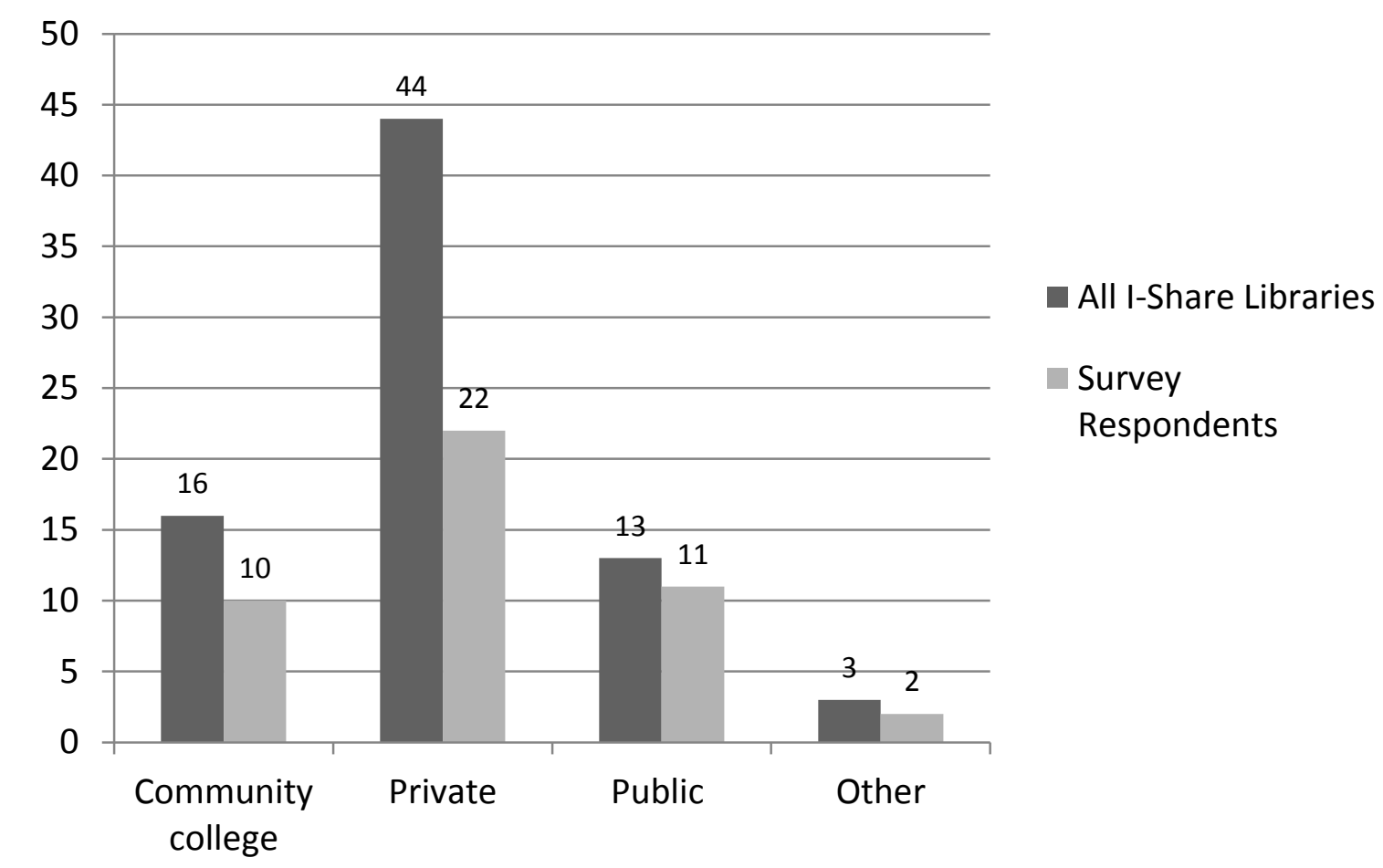

Quantity and type of e-resources available through the catalog

Forty of the 45 survey respondents (89 percent) indicated that their I-Share libraries provide access to some types of e-resources through their catalogs. Of those who catalog e-resources, e-books proved the most common type of resource to catalog and the most numerous in the catalog. Thirtyseven respondents (93 percent) answered that their library catalogs e-books. Twelve respondents (30 percent) indicated that their library catalog includes records for over 10,000 e-book titles. Thirty-one respondents (78 percent) answered that their library catalogs e-journals, and twenty (50 percent) catalog databases. While the survey did not specifically ask for reasons supporting a library's cataloging decision, several respondents volunteered that their library relied on A-Z lists and their website, rather than the catalog, for access to their e-journals and databases. One-third of respondents (13) also 
indicated that they cataloged other types of e-resources, including streaming videos, audio files, digitized images, and datasets. With more multi-media resources available through the Internet, the variety of e-resources available through the catalog may continue to grow. Table 1 provides a breakdown by the type of resource cataloged and number of titles represented in the catalog.

Table 1: Types of E-Resources Cataloged

\begin{tabular}{|l|r|r|r|}
\hline & E-books & E-Journals & Databases \\
\hline No titles in the catalog & $\mathbf{3 ( 8 \% )}$ & $\mathbf{9 ( 2 3 \% )}$ & $\mathbf{2 0}(\mathbf{5 0 \%})$ \\
\hline Total cataloging format & $\mathbf{3 7}(\mathbf{9 3} \%)$ & $\mathbf{3 1}(\mathbf{7 8 \% )}$ & $\mathbf{2 0 ( 5 0 \% )}$ \\
\hline $1-1,000$ titles (1-50 databases) & $7(18 \%)$ & $17(43 \%)$ & $10(25 \%)$ \\
\hline $1,000-5,000$ (50-100 databases) & $15(38 \%)$ & $6(15 \%)$ & $3(8 \%)$ \\
\hline $5,000-10,000$ titles & $3(8 \%)$ & $3(8 \%)$ & \\
\hline $\begin{array}{l}\text { Over 10,000 titles (Over } 100 \\
\text { databases) }\end{array}$ & $12(30 \%)$ & $5(13 \%)$ & $7(18 \%)$ \\
\hline Total Responses & $\mathbf{4 0 ( 1 0 0 \% )}$ & $\mathbf{4 0 ( 1 0 0 \% )}$ & $\mathbf{4 0 ( 1 0 0 \% )}$ \\
\hline
\end{tabular}

Percentages may not add up to $100 \%$ due to rounding.

Single-record versus separate-record approach

Consistent with trends identified in the literature, a majority of libraries that responded follow a separate-record approach to cataloging all e-resources (see Table 2$) \cdot{ }^{47}$ Of those cataloging e-books, twothirds (25 respondents) indicated that they used an exclusively separate-record approach, with only one library indicating an exclusive single-record approach. The approach for e-journals was more mixed, with no one method of cataloging followed by a majority of respondents. An exclusive separate-record approach was the most frequently used (14 respondents), but many respondents reported that their library used a combination of methods (seven respondents) or an exclusive single-record approach (ten respondents). The greater variety of approaches used for e-journals compared with e-books is consistent with the recommendations of the 2003 Task Force, which called for separate records for ebooks, but left the decision of a separate- versus a single-record approach for e-journals up to the individual libraries. Of the respondents using a separate-record approach for e-journals, either 
exclusively or in combination, two-thirds of respondents (14) indicated that they followed the aggregator-neutral guidelines (the Task Force did not ask about provider-neutral guidelines for e-books, as they were too new at the time of the survey).

Table 2: Single versus Separate Record Approach

\begin{tabular}{|l|r|r|}
\hline & E-books & E-journals \\
\hline Number of libraries using separate records & $25(67 \%)$ & $14(45 \%)$ \\
\hline Number of libraries using single records & $1(3 \%)$ & $10(32 \%)$ \\
\hline Number of libraries using combination of methods & $9(24 \%)$ & $7(23 \%)$ \\
\hline Number of libraries that do not know & $2(5 \%)$ & 0 \\
\hline Total & $37(100 \%)$ & $31(100 \%)$ \\
\hline
\end{tabular}

Percentages may not add up to $100 \%$ due to rounding

It should be noted that there was the potential for multiple interpretations of Question 4 in the survey, which asked, "How does your library catalog monographs or monographic sets issued in electronic form?" and "How does your library catalog serials issued in electronic form?" (emphasis in the original). Initially, the 2009 Task Force used the term monograph or e-monograph as interchangeable with e-book, and serial or e-serial as interchangeable with e-journal. The former caused confusion with at least one respondent, who, although the respondent reported that the library cataloged e-books in Question 3, reported on Question 4, "We do not currently own anything that I would characterize as an e-monographs. [sic] For our e-reference we do the same record as other formats." Additionally, the questions asked in Question 4 had two possible interpretations: "What is your library's current cataloging practice?" and "What has been the approach taken for all records in the catalog?" Respondents interpreting the question in the first way would be more likely to report an exclusive practice, while libraries interpreting the question in the second way would be more likely to report mixed practice. These two interpretations were evidenced by the comments left by respondents.

Respondents listed various factors that impacted their library's practice. For libraries following (or preferring to follow) a separate-record approach, the increased use of vendor records and simplicity 
of maintenance were key reasons mentioned in the comments. Ease of use for libraries' end-users was mentioned as a reason for using both the single-record and the separate-record approach. Given the increasing prevalence of vendor records, as demonstrated in the survey results, the number of records following a separate-record approach will likely grow, as several libraries commented that they were transitioning to a separate-record approach for their serials.

\section{Batch loading and vendor records}

As expected, the survey found that many libraries obtain groups of bibliographic records for eresources from outside of OCLC and bring them into their catalog through a batch loading process. Although OCLC was the most popular source for records for e-resources (34 of 39 respondents reported obtaining records from OCLC), over two-thirds of respondents (26) reported receiving records from vendors. Thirty-two respondents (82 percent) reported that their libraries brought records into the catalog via Voyager's bulk import, with seven libraries having loaded over 50,000 records. Figure 2 details the percentage of libraries that have brought records into their catalog via bulk import, and Figure 3 provides details on which vendors have been or will be supplying respondents with records. Records for collections of titles from NetLibrary and Springer are some of the most common vendor record loads because CARLI and its predecessor purchased sets of these e-books for member libraries and coordinated record loads centrally. 


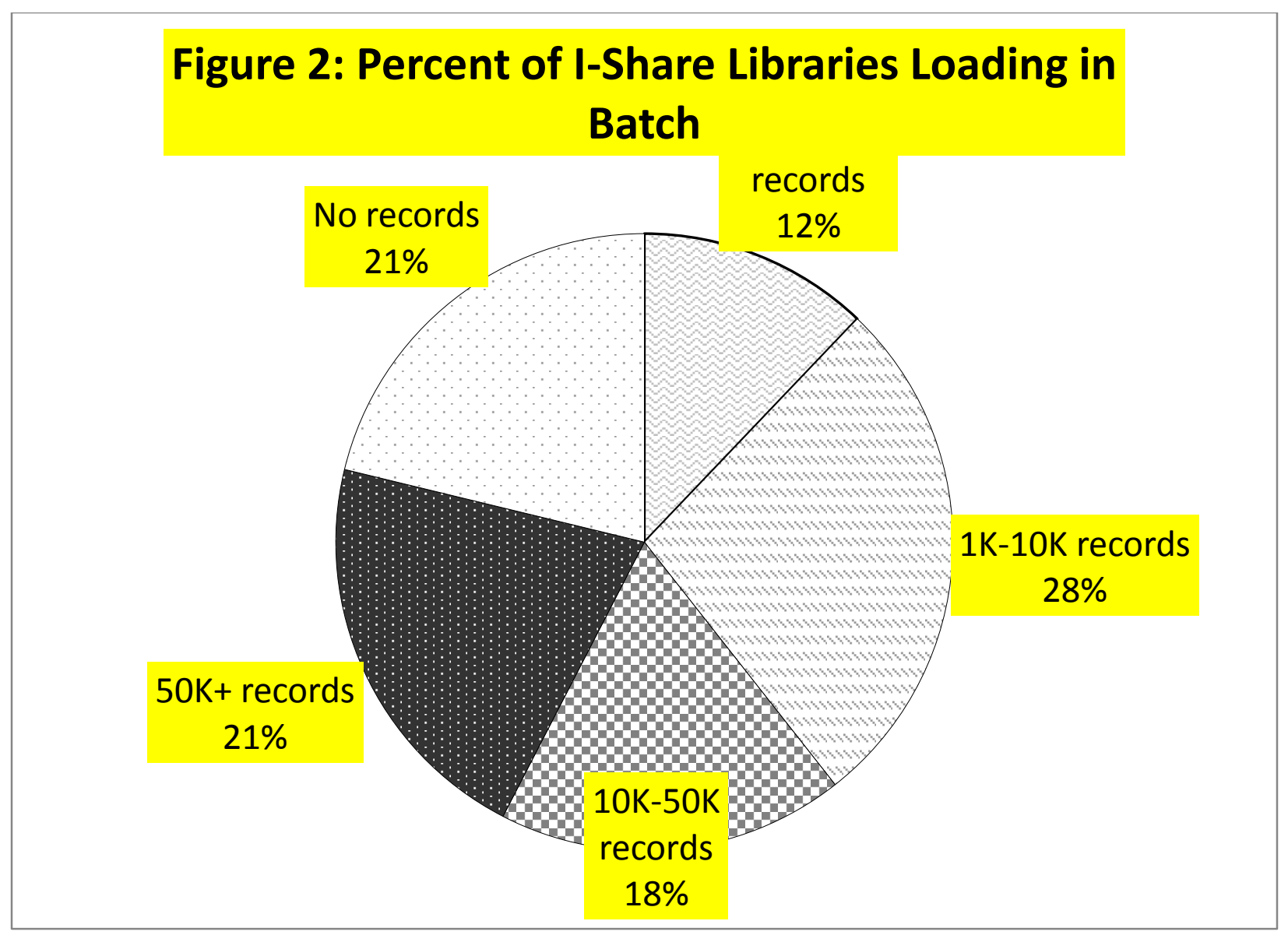




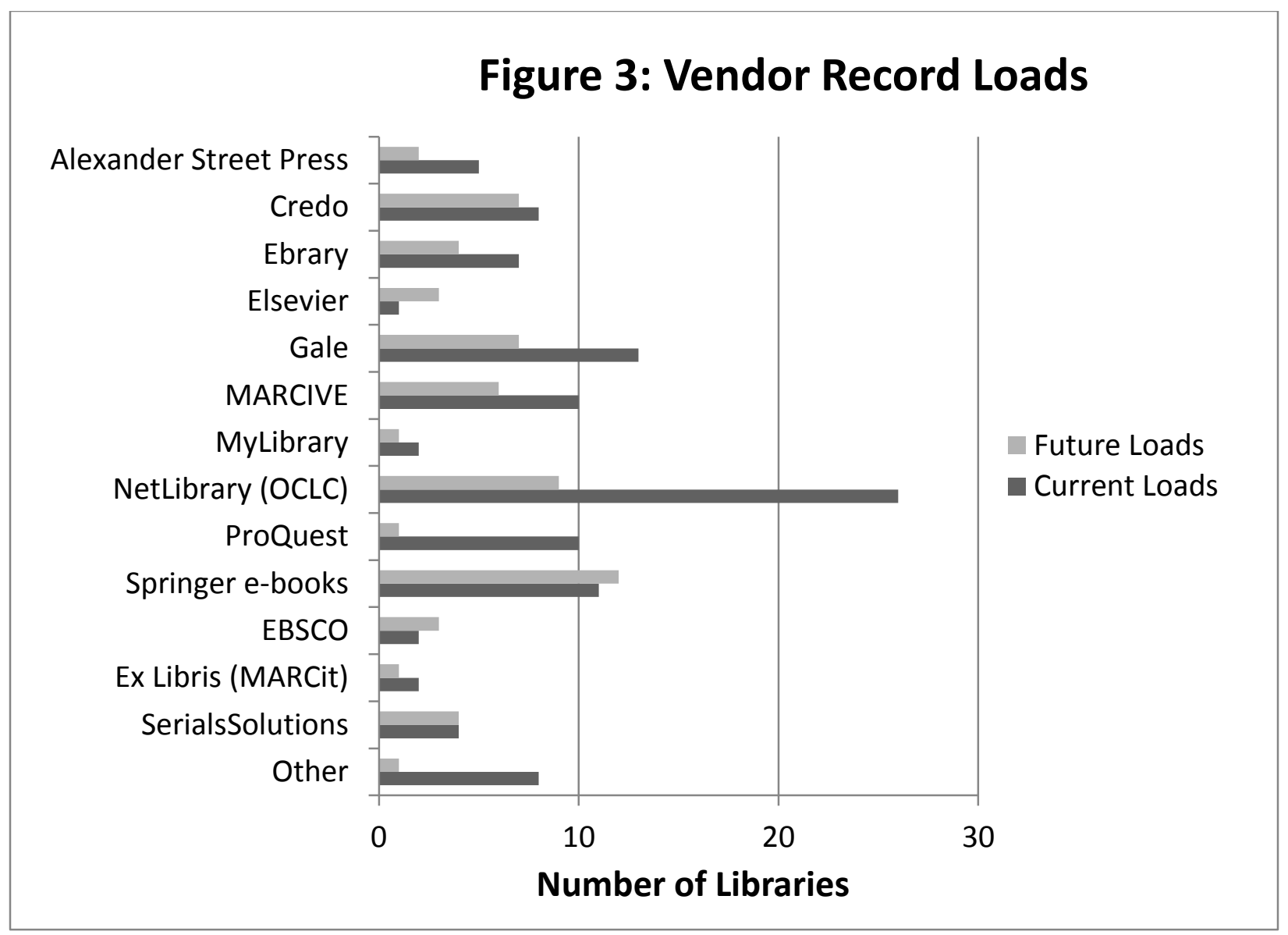

Managing vendor records in batch, as the survey demonstrated, has become commonplace for e-resources cataloging in I-Share libraries and requires some additional skills compared with cataloging titles individually. Comments by respondents identified specific challenges with vendor records, consistent with the literature. These included problems with quality and completeness in the records, issues with batch loading processes, such as special characters or diacritics causing the load to fail, lack of standards and consistency, and difficulty determining an appropriate workflow.

\section{Task Force Recommendations}

The final 2009 Task Force report contains 28 recommendations, grouped into two broad categories. The first 18 recommendations are directly geared toward libraries working in the I-Share consortial environment and the last ten are recommendations directed to CARLI and member advisory 
councils on ways to better support the cataloging activities of member libraries. The recommendations are designed to be used in conjunction with national cataloging standards and guidelines. The 2009 Task Force did not provide recommendations on what to catalog or whether to catalog e-resources, although the final report does provide some guidance in a section entitled, "Things to Consider When Deciding to Catalog E-Resources." Ultimately the 2009 Task Force left this decision up to the individual member libraries, but encouraged members to consider the FRBR user tasks and the specific needs of their library. Recommendations were assigned specific descriptors (e.g., monographs, continuing resources, holdings records, and URLS), which the Task Force used for its own needs and to develop mini-reports on specific issues.

The 2009 Task Force also weighted the importance of its recommendations. Although CARLI and its advisory bodies do not mandate that member libraries follow specific cataloging practices, the Task Force did want to demonstrate that certain recommendations were particularly important. To achieve this, the Task Force assigned one of three levels of rank to each recommendation: level 1-follow without exception; level 2-follow if at all possible; level 3-helpful information that libraries may wish to follow.

\section{Recommendations addressing single versus separate records}

The 2009 Task Force recommended that catalogers create separate bibliographic records for eresources (e.g., one for the print version, one for the electronic version) for both monographs and continuing resources (R1 and R2). This was a departure from 2004 recommendations for I-Share libraries, which had recommended the separate-record approach for monographs, but did not provide a specific recommendation for e-journals. The Task Force chose to recommend separate records for all types of e-resources for three reasons. First, with the growing prevalence and importance of eresources, treating them as an add-on to print records no longer made much sense. Many libraries have 
e-resources but no print counterpart, or may be canceling their print subscriptions in favor of electronic versions. Additionally, many e-resources have no print equivalent, so must be cataloged as an electronic format. The separate-record approach allows for consistency in practice for resources with and without print counterparts, and allows the electronic information to come to the fore of what is being described, should there be distinctive features related to the electronic version. Second, the potential to follow the Functional Requirements for Bibliographic records would be more likely if information about two different formats is not contained on a single record. It would be easier to organize information contained in separate records and break it into the four FRBR entities. New features in catalog interfaces, like facets for format limits, can better take advantage of information if it is clearly indicated

in the records. Third, as shown by the survey, many libraries obtained sets of records from vendors to be loaded in batch into the catalog. Vendor records almost always use a separate-record approach for their content, and managing batch loads and deletions of individual records is a simpler process than trying to add or delete individual fields to existing records. The 2009 Task Force did acknowledge that there may be circumstances where libraries prefer to use a single-record approach, and anticipates having a mixed approach in I-Share libraries for some time into the future.

\section{Provider-neutral and aggregator-neutral records}

The 2009 Task Force recommended that records follow the provider-neutral and aggregatorneutral guidelines for electronic monographs and electronic continuing resources, respectively (R3 and R5), and placed these recommendations at the highest priority level. Previous versions of the Task Force report also recommended using the aggregator-neutral records provided by CONSER, and the 2009 Task Force expanded the recommendations to cover more recent PCC recommendations for provider-neutral records for e-monographs and integrating resources. For libraries managing records for collections of emonographs, the 2009 Task Force recommended placing the provider-specific collection title or vendor 
name in an appropriate local field. This could then be used for internal purposes to collocate all records for e-monographs that have access through a specific provider (R4). This field should assist libraries in identifying a group of records if changes or deletions are necessary in the future. Following a recommendation developed by the Shared Cataloging Program for the University of California Libraries, the Task Force suggested using bibliographic Local Added Entry fields 791 or 797 to record vendor names or Local Added Entry field 793 for collection titles. ${ }^{48}$ Libraries using a MARC record service might wish to use their default field for collection name (e.g., 949 for Serials Solutions' 360 MARC service).

URLS

The Task Force devoted a substantial section of the recommendations and its own deliberations to the issue of the placement of URLs. Survey results indicated that this was an area where member libraries felt the most confused, and it also was an area where standardized practice is extremely helpful for end-users of the I-Share union catalog. Consideration of how to provide access to electronic resources is arguably the most important aspect of cataloging electronic resources, as this is what allows users to directly access the content from the catalog. Recommendations of the 2003 Task Force had placed an emphasis on retaining "shareable" URLs that could be used by other ILCSO libraries that might use the record as a basis for copy cataloging. A "shareable" URL is defined as a hyperlink that will work for end-users affiliated with any institution that has a subscription to the resource, and, therefore, access rights. Libraries were instructed to place their URLs in holdings records and the 856 field in the bibliographic record was suppressed from display in the I-Share union catalog. Within their individual library catalogs, libraries had the option to display or suppress the 856 field in the bibliographic record. However, with the introduction in 2008 of VuFind as an option for individual library catalog displays, the decision to display the 856 in the bibliographic record was made centrally for all individual library catalogs. Suddenly libraries that previously had suppressed display of 856 fields in the bibliographic 
record had them displaying again. To address this situation, the 2009 Task Force dropped the previous recommendation to preserve sharable URLs as an access point in the bibliographic record, either by maintaining them in an 856 field or by moving them to a local note field (596) that did not display to end-users.

The new recommendations developed by the 2009 Task Force are designed to address new challenges in display and cataloging practice that had occurred over the past five years, and to simplify and standardize information and notes. Standardized practice makes it easy for end-users to identify the proper URL for their home library and makes it obvious if access is restricted for other libraries. During its deliberations, the Task Force asked three questions that should be considered by any library or consortium developing recommendations: How do national standards and guidelines recommend recording URLs in the record and using the 856 subfields? What are the current methods used to record URLs, how are the 856 subfields used, and how much clean-up will be required if new recommendations are formulated? How will the 856 field display within the local and/or shared environment? The most important recommendations for URL placement and construction are as follows:

- Place URLs in the 856 field, subfield u of holdings record and, optionally, in the same area of the bibliographic record (R10 and R11). The 856 field in the bibliographic record is suppressed from display in the I-Share union catalog, so the URL must be placed in the holdings record to be available in the union catalog.

- Libraries may choose to whether to keep or remove, and display or suppress 856 field(s) in bibliographic records (R11). URLs available in the bibliographic 856 field should either be constructed in a form that can be used by the institution's end-users, whether shareable or institution-specific, or else be removed.

- Construct 856 field(s) in a manner that focuses on the shared environment display by utilizing a consistent method for recording notes for content and restriction (R15) 
- Subfield 3: Provider or package name, if appropriate, and/or coverage/part information, if appropriate

○ Subfield z: Note of restriction and institutional identification, if appropriate

- Subfield u: URL appropriate to the institution

- Subfield y: Link text (optional) ${ }^{49}$

The 2009 Task Force provided a list of reasons why a library might wish to retain URLs in the bibliographic record: one, batch loaded records need to have an 856 field in the bibliographic record in order for it to be copied into the holdings record during the loading process; two, 856 fields, with the proper indicators, display in the results list in VuFind, making access to the e-resources more obvious; and three, having an 856 field in the bibliographic record may facilitate migration and re-use of catalog data in other applications, such as web-scale discovery systems. On the other hand, if present, a URL in the bibliographic record will be visually separate in an online display from any corresponding local holdings information (e.g., years of coverage), require additional maintenance, and possibly additional steps in a cataloging workflow.

Finally, the 2009 Task Force considered the issue of currency and accuracy of URLs in the catalog. Survey results indicated that approximately two-thirds of respondents verified URLs at the time of cataloging and performed link checking, although this was generally through spot checking and student projects, as opposed to the use of link-checking software. To lower the maintenance burden, the Task Force recommended that catalogers select stable and/or persistent URLs, when available (R12). The previous Task Force's recommendations to verify URLs at the time of cataloging and keep them current were retained (R13 and R14). Methods for keeping URLs current in the Voyager system are limited, and the Task Force recommended that CARLI revisit a search for link checking software for libraries (R20). 


\section{Areas for further consortial help}

The creation and maintenance of a shared catalog requires support and effort from both the consortium itself and its member libraries. The last ten recommendations in the report were directed to CARLI and its governing bodies. These included recommendations for enhancements, specific to CARLI's software environment that would make e-resources cataloging simpler and titles more accessible, such as allowing libraries to be able to display or suppress the 856 field in their local catalog interfaces (R19) and improving the display of ancillary URLS (R28). The recommendations also called for additional training and support for libraries cataloging e-resources and managing batch loads. Work on addressing these recommendations has been underway. CARLI sponsored a MarcEdit workshop in the fall of 2010, developed an online request form that included documentation designed to walk libraries through the batch-loading process, and updated consortial documentation to make it consistent with the new recommendations.

\section{Mini-reports}

The 2009 Task Force recognized that, like the preceding Task Force's report, its final report was dense, lengthy, and written for multiple audiences. In order to provide a ready reference for catalogers actively cataloging e-resources and a graphical representation of the information in the recommendations, the 2009 Task Force developed mini-reports on three topics: cataloging an e-book, cataloging an e-journal, and batch loading records. The smaller reports take advantage of the descriptors assigned to the recommendations by allowing recommendations to be selected based on topic. The mini-reports provide a flow chart that steps catalogers through the applicable recommendations as well as the full text of the relevant recommendations on the topic. The report on batch loading also includes a cheat sheet for transforming provider-specific e-monograph records into provider-neutral ones. These smaller reports are designed to be useful for training and reference, and to 
make the entire report more accessible. All of the mini-reports are available on the 2009 Task Force website. ${ }^{50}$

\section{Conclusion}

As the survey of I-Share libraries and the subsequent recommendations developed by the 2009 Task Force reveal, managing access to e-resources through the library catalog is of continued importance to libraries. Almost all I-Share libraries provide access to e-resources-e-journals, e-books, and/or databases - through the library catalog. I-Share library members strive to make recorded data in their catalogs useful to based on the current information-seeking behaviors of their end-users, and have struggled with many of the same questions as were explored in the review of the literature. Individual libraries can attempt to do this more effectively and economically by joining a consortium such as CARLI whose collaborative and leadership strategy embodies the education of its member libraries on issues, innovations, services and best practices for physical and digital collections. ${ }^{51}$ One way this is accomplished is to charge a task force of member volunteers, such as the 2009 Task Force, to apply their array of experiences in study, and make best-practice recommendations.

The 2009 Task Force felt strongly that conducting a survey was an appropriate first step in the study process. It was designed to focus entirely on CARLI's I-Share libraries. Its purpose was to determine how these members were cataloging their remotely accessed resources, their awareness of and/or compliance with existing consortial recommendations, and the challenges faced with e-resources cataloging practices. While many of the responses are specific to I-Share and its union catalog, the survey results can be of benefit to other consortia (or individual libraries) developing or revising their own guidelines for cataloging e-resources, taking I-Share's experiences into account. The survey revealed important tendencies and imparted lessons learned before recommendation revisions began. 
First, the libraries were more inclined to choose their cataloging practice based on ease of application. At the forefront is what they believe will be of assistance to their local end-users, regardless of whether this conflicts with consortial guidelines. Any recommendations created need to take this into account. Complicated or confusing recommendations that require additional time and effort on the part of member libraries but do not have an obvious payoff will not be followed. This was particularly evident in the responses regarding the URL, where the previous Task Force's recommendations for maintaining shareable URLs in bibliographic records were complex and poorly understood. Most libraries did not follow the recommendation to maintain shareable URLs in the records and many respondents had no idea how to do this.

Second, survey comments indicated that many libraries are open to simple and straightforward guidelines and welcome direction from the consortium. I-Share libraries indicated a willingness to learn and apply recommendations, as long as they could be applied quickly and consistently and would benefit their end-users. Some comments received on the survey that support this conclusion are:

- " "I'd love to take a workshop on how to efficiently handle these resources."

- $\quad$ "Let us know what you want us to do, without cluttering up the catalog!"

- "Here's where we need guidance from the ICAT group!"

- $\quad$ "Feel free to do more training and standardization!"

To achieve simplicity, the 2009 Task Force used several approaches. The use of descriptors helped to categorize the recommendations and break them up into smaller groups, and were used to develop the targeted mini-reports, and can facilitate searching the online document for a compilation of specific recommendations. The 2009 Task Force provided ready-reference flow charts of step-by-step procedures in three major areas of e-resources cataloging: e-book records, e-journal records, and batch loading records. Wherever appropriate, the 2009 Task Force employed examples within recommendations to convey visual interpretation. Members of the 2009 Task Force analyzed public 
catalog views whenever recommendations affected display and engaged CARLI's staff to provide appropriate tables of what end-users would see as a result..$^{52}$ Because I-Share libraries cannot be mandated to follow specific cataloging practices, the 2009 Task Force ranked their recommendations at three different levels in order to achieve order of importance. All of these strategies were designed to break up the report into manageable chunks, make the information contained within more accessible to member libraries, and thus have more libraries willing and able to follow the recommendations.

Third, some terminology in the survey proved unclear or not well-defined. For example, the 2009 Task Force's interchangeable use of e-book and e-monograph, or e-serial and e-journal was open to ambiguity and diverse interpretation. In retrospect, it would have been better if the survey instrument used consistent terminology across all questions. However, these unforeseen outcomes enabled the 2009 Task Force to embrace consistent terminology when developing recommendations and preparing a glossary of terms in its final report.

Fourth, while a 59 percent response rate was appropriate for analysis, the Task Force failed to reach 41 percent of I-Share members. Follow-up telephone calls with non-respondents might have shed some light on other questions, such as the apparent lack of understanding or awareness of the former guidelines. The 2009 Task Force might have analyzed the length of an institution's CARLI membership and explored whether that might have been a contributing factor. Newer members could be struggling with adjustment to a new system, governance issues, staff learning curves, and/or an updating of staffing positions. A survey during these processes might prove to be intimidating or challenging. Further follow-up with both respondents and non-respondents might have led to a more useful final product.

So what will be the final verdict on the 2009 Task Force recommendations? Do they adequately address the needs of member libraries for providing access to e-resources? While the 2009 Task Force's report and recommendations can be beneficial to member libraries, there are also limitations in what it can do to shape cataloging practices and to make it easier to provide access to e-resources. CARLI and its 
governing bodies do not have the power to mandate, only to recommend. While shared purchases of eresource collections can place the consortium in a position of greater influence over the content of a group of bibliographic records, most e-resource purchasing and cataloging are done by individual members. A notable recent example is the Springer e-book collection purchase, in which CARLI has been able to obtain the record set, modify the record set in light of the Task Force recommendations, and provide assistance to individual libraries who wanted to load the records into their local catalogs. Additional consortial purchasing or brokering of consortial deals should continue to follow this example, but for e-resources that come from myriad sources outside of CARLI, the ability of the consortium to assist and regulate is more limited.

The 2009 Task Force, as a goal-specific group, was officially disbanded with thanks shortly after presenting its report to the I-Share User's Group. Responsibility for publicizing the final report has been left to CARLI and its governing bodies. The 2009 Task Force did not make any recommendations on the frequency or type of membership investigations after the final report was made available. It did not speculate on a specific time frame for a fourth iteration of the Task Force. However, a strong commitment prevailed among the members of the 2009 Task Force, even after their charge was complete, to help with or lend their expertise in continuing education efforts, particularly as proposed in the last ten recommendations directed toward CARLI administration. The 2009 Task Force is certain, however, that the recommendations will need to be revisited as new technologies such as open-source catalogs and discovery services, cataloging precepts such as FRBR, and cataloging principles and rules such as RDA are implemented in the near future.

\footnotetext{
${ }^{1}$ CARLI, Cataloging Electronic Resources/Electronic Resources Display in the OPAC Task Force (2009), http://www.carli.illinois.edu/comms/iug/iug-cater2009.html (accessed April 14, 2011).
} 
${ }^{2}$ Xiaotian Chen et al., "E-Resource Cataloging Practices: A Survey of Academic Libraries and Consortia,"

Serials Librarian 47, no. 1/2 (2004), 153-179. http://dx.doi.org/10.1300/J123v47n01 11.

${ }^{3}$ Chen, "E-Resource Cataloging Practices," 155.

${ }^{4}$ Lisa Hanson O'Hara, "Providing Access to Electronic Journals in Academic Libraries: A General Survey,"

Serials Librarian 51, no. 3/4 (2007): 119-128. http://dx.doi.org/10.1300/J123v51n03 08.

${ }^{5}$ O’Hara, "Providing Access to Electronic Journals in Academic Libraries: A General Survey," 126.

${ }^{6}$ Colleen Cuddy and Ellen Bahr, "Trends in Cataloging Electronic Journals in Health Sciences Libraries:

Will Title Lists or the Online Catalog Prevail?" Journal of Electronic Resources in Medical Libraries 3, no. 3

(2006): 37-59. http://dx.doi.org/10.1300/J383v03n03 03.

7 O’Hara, “Providing Access to Electronic Journals in Academic Libraries," 126-7.

${ }^{8}$ Xiaotian Chen and Stephen Wynn, "E-Journal Cataloging in an Age of Alternatives: A Survey of

Academic Libraries," Serials Librarian 57, no. 1/2 (2009): 96-110.

http://dx.doi.org/10.1080/03615260802669110.

${ }^{9}$ Maria Collins, "Electronic Journal Forum: The Effects of E-Journal Management Tools and Services on

Serials Cataloging," Serials Review 31, no. 4 (2005), 291-7.

http://dx.doi.org/10.1016/j.serrev.2005.08.002.

${ }^{10}$ Rebecca Kemp, "MARC Record Services: A Comparative Study of Library Practices and Perceptions,"

Serials Librarian 55, no. 3 (2008), 410. http://dx.doi.org/10.1080/03615260802056367.

${ }^{11}$ Jacqueline Belanger, "Cataloguing E-books in UK Higher Education Libraries: Report of a Survey,"

Program: Electronic Library and Information Systems 41, no. 3 (2007): 203-16.

http://dx.doi.org/10.1108/00330330710774093.

${ }^{12}$ Andrea Dinkelman and Kristine Stacy-Bates, "Accessing E-books through Academic Library Web Sites," College \& Research Libraries 68, no. 1 (Jan. 2007): 45-58.

http://crl.acrl.org/content/68/1/45.full.pdf+html. 
${ }^{13}$ Jane Hutton, “Academic Libraries as Digital Gateways: Linking Students to the Burgeoning Wealth of Open Online Collections," Journal of Library Administration 48, no. 3/4 (2008): 495-507. http://dx.doi.org/10.1080/01930820802289615.

${ }^{14}$ For example, see Dennis Dillon, “E-books: The University of Texas Experience, Part 2," Library Hi Tech 19, no. 4 (2001): 350-62; Susan Gibbons, NetLibrary eBook Usage at the University of Rochester Libraries (Rochester, N.Y.: University of Rochester Libraries, 2001), http://www.lib.rochester.edu/main/ebooks/analysis.pdf (accessed April 14, 2011).

${ }^{15}$ Kristin E. Martin, “ATG Special Report - Cataloging eBooks: An Overview of Issues and Challenges," Against the Grain 19, no. 1 (February, 2007): 45-47.

${ }^{16}$ Robert Bothmann, “Cataloging Electronic Books," Library Resources \& Technical Services 48, no. 1 (January, 2004): 12-19.

${ }^{17}$ Kyle Banerjee, "Taking Advantage of Outsourcing Options: Using Purchased Record Sets to Maximize Cataloging Effectiveness," Cataloging \& Classification Quarterly 32, no. 1 (2001), 55-64, http://dx.doi.org/10.1300/J104v32n01 05; Deborah E. Kulczak and Cathy Reineka, "Marcive GPO Records and Authority Control: An Evaluation of Name and Subject Headings at the University of Arkansas Libraries," Cataloging \& Classification Quarterly 38, no. 1 (2004), 87-103, http://dx.doi.org/10.1300/J104v38n01 08; Laura D. Shedenhelm and Bartley A. Burk, "Book Vendor Records in the OCLC Database: Boon or Bane?" Library Resources \& Technical Services 45, no. 1 (January, 2001), 10-19.

${ }^{18}$ Kristin E. Martin and Kavita Mundle, "Cataloging E-Books and Vendor Records: A Case Study at the University of Illinois at Chicago," Library Resources \& Technical Services 54, no. 4 (October, 2010), 22737.

${ }^{19}$ Kavita Mundle, "Integration of Electronic Books into Library Catalogs: The UIC Library Experience," Acquisitions Librarian 19, no. 3/4 (2007), 389-407; Rebecca L. Mugridge and Jeff Edmunds, "Using 
Batchloading to Improve Access to Electronic and Microform Collections," Library Resources \& Technical Services 53, no. 1 (January, 2009), 53-61; Annie Wu and Anne M. Mitchell, "Mass Management of EBook Catalog Records: Approaches, Challenges, and Solutions," Library Resources \& Technical Services 54, no.3 (2010), 164-74.

${ }^{20}$ Elaine Sanchez, et al., "Cleanup of NetLibrary Cataloging Records: A Methodical Front-End Process," Technical Services Quarterly 23, no. 4 (2006), 51-71; Martin and Mundle, "Cataloging E-Books and Vendor Records," 227-37; Wu and Mitchell, "Mass Management of E-Book Catalog Records," 164-74. ${ }^{21}$ Serials Solutions, "Serials Solutions Introduces a New and Improved Serials Solutions 360 MARC Updates Service," Jan 10, 2008, http://www.serialssolutions.com/news/detail/serials-solutionsintroduces-a-new-and-improved-serials-solutions-360-marc-/ (accessed April 14, 2011).

${ }^{22}$ Martin and Mundle, "Cataloging E-Books and Vendor Records," 230.

${ }^{23}$ Wu and Mitchell, "Mass Management of E-Book Catalog Records," 173.

${ }^{24}$ Diane Dates Casey, "The Impact of Consortial Guidelines on the Cataloging of Internet Resources," Journal of Internet Cataloging 6, no. 1 (2003): 43-54, http://dx.doi.org/10.1300/J141v06n01 06; Cataloging Electronic Resources/Electronic Resources Display in the OPAC Task Force. Final Report (Champaign, IL: ILCSO, 2004); Chew Chiat Naun and Susan M. Braxton, "Developing Recommendations for Consortial Cataloging of Electronic Resources: Lessons Learned," Library Collections, Acquisitions, and Technical Services 29, no. 3 (2005): 307-25. http://dx.doi.org/10.1016/j.lcats.2005.08.005.

${ }^{25}$ Karen Cary and Joyce L. Ogburn, “Developing a Consortial Approach to Cataloging and Intellectual Access," Library Collections, Acquisitions, and Technical Services 24, no. 1 (2000): 45-51. http://dx.doi.org/10.1016/S1464-9055(99)00095-0.

${ }^{26}$ Paul Moeller and Wendy Baia, recorded by Jennifer O'Connell, "Cataloging for Consortium Catalogs," Serials Librarian 44, no. 3/4 (2003): 229-35. http://dx.doi.org/10.1300/J123v44n03 12. 
${ }^{27}$ Elizabeth McDonald and Joyce Johnston, "Showtime! Cataloging and Providing Access to Streaming Video Records in the Online Catalog," Tennessee Libraries 58, no. 2 (2008).

${ }^{28}$ Carrie A Preston, "Cooperative E-book Cataloging in the OhioLINK Library Consortium," Cataloging \& Classification Quarterly 49, no. 4 (forthcoming).

${ }^{29}$ Roxanne Sellberg, "Cooperative Cataloging in a Post-OPAC World," Cataloging \& Classification Quarterly 48, no. 2 (2010): 241. http://dx.doi.org/10.1080/01639370903535734.

${ }^{30}$ Sellberg, "Cooperative Cataloging in a Post-OPAC World," 244.

${ }^{31}$ CONSER Cataloging Manual, Module 31.2.3.B.,Separate Records: The Aggregator Neutral Record (Washington, D.C.: CONSER, 2002), http://www.loc.gov/acq/conser/guidelines.pdf (accessed April 14, 2011).

${ }^{32}$ Carol Hixson, David Banush, Ana Cristán, eds. BIBCO Participants' Manual, Appendix A. Integrating Resources: A Cataloging Manual (Washington, D.C.: Program for Cooperative Cataloging, 2002), http://www.loc.gov/catdir/pcc/bibco/irman.pdf (accessed April 14, 2011).

${ }^{33}$ Becky Culbertson, Yael Madelstam, and George Prager, Provider-Neutral E-Monograph MARC Record Guide (Washington, D.C.: Program for Cooperative Cataloging, 2009), http://www.loc.gov/catdir/pcc/bibco/PN-Guide.pdf (accessed April 14, 2011).

${ }^{34}$ Wu and Mitchell, “Mass Management of E-Book Catalog Records,” 164-174.

35 “PCC Participants' Meeting Summary, ALA Midwinter-San Diego, January 9, 2011, US RDA Test Participant's Panel Discussion," Program for Cooperative Cataloging, http://www.loc.gov/catdir/pcc/PCC ParticipantsMeeting Minutes 11m.html (accessed April 14, 2011). ${ }^{36}$ IFLA Study Group on the Functional Requirements for Bibliographic Record. Functional Requirements for Bibliographic Records: Final Report. Munich: K.G. Saur, September 1997, as amended and corrected through February 2009: 8. http://www.ifla.org/files/cataloguing/frbr/frbr 2008.pdf (accessed April 14, 2011). 
${ }^{37}$ Julian Everett Allgood, "Serials and Multiple Versions, or the Inexorable Trend Toward Work-Level Displays," Library Resources \& Technical Services 51, no. 3 (July, 2007): 160.

${ }^{38}$ Robert E. Wolverton Jr. and Kristin Antelman, "Conference Report: The FRBR Frontier: Applying a New Bibliographic Model to E-Resources," Serials Librarian 53, no. 4 (February, 2008): 218.

39 Jason Vaughan, “Web Scale Discovery Services," Library Technology Reports 47, no. 1 (January 2011), $5-61$.

40 Daniel A. Freeman, "Jason Vaughan Discusses Web Scale Discovery Systems" interview submitted to ALA TechSource [blog] on February 4, 2011 - 9:11am.

http://www.alatechsource.org/blog/2011/02/jason-vaughan-discusses-web-scale-discoverysystems.html (accessed April 14, 2011).

${ }^{41}$ Marshall Breeding, "Opening Up Library Systems through Web Services and SOA: Hype, Or Reality," Library Technology Reports 45, no. 8 (November/December 2009): 1-42.

42 Kristin Antelman, Emily Lynema, and Andrew K. Pace, "Toward a Twenty-First Century Library Catalog," Information Technology \& Libraries 25, no. 3 (September 2006): 128-39.

${ }^{43}$ Jennifer Bowen, "Metadata to Support Next-Generation Library Resource Discovery: Lessons from the eXtensible Catalog, Phase 1," Information Technology \& Libraries 27, no. 2 (June, 2008): 5-19.

${ }^{44}$ Jenny Emanuel and M. K. Kern, "Next Generation Catalogs: What Do They Do and Why Should We Care?" Reference \& User Services Quarterly 49, no. 2 (Winter, 2009): 117-20.

${ }^{45}$ Prior to 1998, the ILCSO consortium (CARLI's predecessor) used a continually upgraded version of LCS (Library Computer System) as its integrated library system. ILCSO migrated to DRA classic in 1998. Some previous recommendations for cataloging e-resources were a direct result of the limitations of these earlier systems. 
${ }^{46}$ Cataloging Electronic Resources/Electronic Resources Display in the OPAC Task Force (2009), "Final Report," June 30, 2010, http://www.carli.illinois.edu/comms/iug/iug-cater2009.html (accessed April 14, 2011).

${ }^{47}$ The information in Table 2 is taken from answers to Question 4 in the original survey. Answers to the question regarding the single record/separate record approach for e-books differ slightly from Appendix B in the Final Report. In writing this paper, the authors reviewed the survey results and revised the answers for two respondents, based on information they provided in the comments field.

${ }^{48}$ SOPAG Electronic Resources Cataloging Task Force, "CDL Conventions for Cataloging Electronic Resources," 1999, rev. Sept. 2009

http://www.cdlib.org/services/collections/scp/docs/cdlcatalogingguidelines.pdf (accessed April 14, 2011).

${ }^{49}$ When testing the 856 field in the I-Share environment, the Task Force revealed some bugs in the display of the 856 subfield y within WebVoyáge, which is why the Task Force chose to leave its use as optional even though the subfield provides elegant link text within VuFind.

${ }^{50}$ CARLI, Cataloging Electronic Resources/Electronic Display in the OPAC Task Force (2009), http://www.carli.illinois.edu/comms/iug/iug-cater2009.html.

${ }^{51}$ Consortium of Academic and Research Libraries in Illinois, "Strategic Priorities" on About CARLI Homepage http://www.carli.illinois.edu/about/about-priorities.html (accessed April 14, 2011).

${ }^{52}$ Because of contractual agreements with Ex Libris, visual representations of the Voyager software have been removed from the publicly accessible version of the Final Report. 